\title{
Desempenho de filmes comestíveis em comparação ao filme de policloreto de vinila na qualidade pós-colheita de mexericas 'Poncã'
}

\author{
Performance of edible films in comparison to the polyvinyl chloride film in the post-harvest tangerines \\ 'Ponkan'
}

\author{
Danielle Fabiola Pereira SilvaI ${ }^{I}$ Dalmo Lopes SiqueiraII Rosana Gonçalves Pires Matias ${ }^{\text {II }}$ Sílvia Paula \\ Oliveira ${ }^{\text {II }}$ Leila Cristina Rosa de Lins ${ }^{\text {II }}$ Luiz Carlos Chamhum Salomão ${ }^{\text {II }}$
}

\begin{abstract}
- NOTA -
RESUMO

O objetivo do trabalho foi avaliar o efeito de diferentes concentrações de fécula de mandioca na vida útil pós-colheita de frutos 'Mexerica Poncã' durante o armazenamento em temperatura ambiente em substituição ao filme de policloreto de vinila (PVC). Os frutos foram imersos em suspensões aquosas de fécula de mandioca a $0 ; 1 ; 2$ e $3 \%$ (m:v) acrescidas de 0,5mL $L^{-1}$ de óleo mineral Assist (Bayer Cropscience, da empresa Hoechst Schering AgrEvo UK Ltd. Inglaterra) ou recobertos com PVC de $14 \mu m$ de espessura, $e$ armazenados a temperatura ambiente. As amostragens foram realizadas no tempo zero (início do experimento) e a cada dois

and $3 \%(\mathrm{~m} / \mathrm{v})$ plus $0.5 \mathrm{~mL} \mathrm{~L}^{-1}$ a mineral oil Assist (Bayer CropScience, company Hoechst Schering AgrEvo UK Ltd. Inglaterra) and the film of polyvinyl chloride (PVC) of $14 \mu \mathrm{m}$ thick, and stored at room temperature. The samples were collected at time zero (day of the assembly of the experiment) and then every two days. We evaluated the weight loss, juice yield, soluble solids (SS), titratable acidity (TA), SS / TA and ascorbic acid. The weight loss increased during storage, being more pronounced at a dose of $2 \%$. The reduction in ascorbic acid content was higher in fruits covered with PVC film. The concentration of cassava starch to $1 \%$ was the highest values for the maintenance of physical and chemical quality of fruits of 'Mexerica Poncã' during eight days of storage.
\end{abstract} dias, por oito dias. Foram avaliadas a perda de massa fresca, rendimento de suco, sólidos solúveis (SS), acidez titulável (AT), relação SS/AT e teor de ácido ascórbico. A perda de massa fresca aumentou durante o armazenamento, sendo mais acentuada na dose de $2 \%$. A redução no teor de ácido ascórbico foi maior nos frutos recobertos com filme de PVC. A concentração de fécula de mandioca a $1 \%$ foi a que proporcionou melhores resultados quanto à manutenção da qualidade físico-química de frutos de 'Mexerica Poncã' durante oito dias de armazenamento.

Palavras-chave: Citrus reticulata, fécula de mandioca, conservação, filme comestível.

\section{ABSTRACT}

The objective of this study was to evaluate the effect of different concentrations of cassava starch in postharvest life of fruits 'Tangerine Poncã' during storage at room temperature instead the film of polyvinyl chloride $(P V C)$. The fruits were immersed in aqueous suspensions of cassava starch at 0, 1,2
Key words: Citrus reticulata, cassava starch, conservation, edible film.

Dentre as diversas cultivares de mexerica, a Poncã é a mais cultivada no Brasil por apresentar frutos de boa qualidade e obter excelente aceitação no mercado de frutas in natura. Devido à colheita sazonal, há interesse comercial em estender a oferta desse fruto para o consumidor durante um período mais prolongado. Todavia, as frutas cítricas apresentam perda de qualidade visual com o armazenamento, sendo o processo de transpiração a causa principal da perda de massa fresca (ALVES et al., 2010).

A modificação da atmosfera pela utilização de filmes permite a redução da perda de massa de

IUniversidade Federal de Viçosa (UFV), Av. P.H. Rolfs, s/n, 69908-970, Viçosa, MG, Brasil. E-mail: danieele@ufv.br. Autor para correspondência.

IIDepartamento de Fitotecnia, UFV, Viçosa, MG, Brasil. 
matéria fresca e a manutenção da qualidade de frutos (HENRIQUE \& CEREDA, 2007). A proteção com produto biodegradável tenta desempenhar a mesma função do filme plástico. Revestimentos comestíveis podem ser usados para inibir a migração da umidade, oxigênio, dióxido de carbono, aromas e lipídios, além de introduzir aditivos como antioxidantes e antimicrobianos, melhorando assim as características intrínsecas e a integridade mecânica dos vegetais recobertos (BOTREL et al., 2010).

O amido extraído da mandioca apresenta boas características para formação de películas que, além de serem comestíveis, são de baixo custo, quando comparadas às ceras comerciais. Essa película apresenta bom aspecto, não é pegajosa, é brilhante e transparente, melhorando o aspecto visual dos frutos, e pode ser removida com água (HENRIQUE \& CEREDA, 2007). Existem muitos trabalhos focando o uso de filmes a base de amido em frutas, como em morango (CAMPOS et al., 2011), pera (BOTREL et al., 2010) e manga (SCANAVACA JÚNIOR et al., 2007), todavia para mexerica não foi encontrado.

O desenvolvimento de filmes comestíveis e coberturas com permeabilidade seletiva pode ser extremamente promissor no controle de mudanças respiratórias e aumento do período de conservação de produtos vegetais frescos, como a mexerica 'Poncã' . Dessa forma, o objetivo deste trabalho foi avaliar o efeito de diferentes concentrações de fécula de mandioca na vida útil pós-colheita de frutos de 'Mexerica Poncã' (Citrus reticulata Blanco) armazenados em temperatura ambiente.

Frutos fisiologicamente maduros foram obtidos no pomar experimental da Universidade Federal de Viçosa, em Viçosa- MG (21ํำ' S, 4257'W, 651m de altitude), em maio de 2010. Após a lavagem em água corrente clorada, os frutos foram imersos por cinco minutos em suspensões aquosas em temperatura ambiente de fécula de mandioca a $0 ; 1 ; 2$ e $3 \%$ (m:v), acrescidas de $0,5 \mathrm{~mL} \mathrm{~L}^{-1}$ de óleo mineral Assist (Bayer Cropscience da empresa Hoechst Schering AgrEvo UK Ltd. - Inglaterra) ou recobertos com filme de policloreto de vinila (PVC) de $14 \mu \mathrm{m}$ de espessura. Após a imersão nas diferentes suspensões de fécula de mandioca, os frutos foram dispostos na bancada do laboratório e secos em temperatura ambiente $\left(21 \pm 1,4^{\circ} \mathrm{C}\right)$. A solução de fécula foi preparada acrescentando-se à mistura $1000 \mathrm{~mL}$ de água corrente clorada nas diferentes concentrações de fécula de mandioca comercial (AMAFIL-Cianorte- PR, Brasil), até $70^{\circ} \mathrm{C}$ (HENRIQUE \&CEREDA, 2007).

Após secos os frutos, foram acondicionados em bandejas de poliestireno (220mm x 140mm x 40mm)e armazenados a $22,0 \pm 1,2^{\circ} \mathrm{C}$ e umidade relativa de $85 \pm 5 \%$, por oito dias. As amostragens foram realizadas no tempo zero (dia da montagem do experimento) e a cada dois dias.

Os frutos foram avaliados quanto à perda de massa fresca $(\%)$, determinada por gravimetria, considerando-se a diferença entre o peso inicial do fruto e o obtido em cada amostragem; rendimento de suco (\%), calculado pela relação entre o peso de suco/ peso do fruto; teor de sólidos solúveis $\left({ }^{\circ} \mathrm{Brix}\right)$, determinado usando refratômetro digital (AOAC, 1997); acidez titulável, determinada por titulação do suco com $\mathrm{NaOH} \mathrm{a} 0,1 \mathrm{~N}$ e expressa em porcentagem de ácido cítrico (AOAC, 1997); relação entre sólidos solúveis e acidez titulável e teor de ácido ascórbico, determinado por titulação com reagente de Tillman [2,6 diclorofenolindofenol (sal sódico) a 0,1\%] (AOAC, 1997), com os resultados expressos em mg de ácido ascórbico $100 \mathrm{~g}^{-1}$ de amostra.

$\mathrm{O}$ experimento foi conduzido em delineamento inteiramente casualizado, em parcelas subdivididas com três repetições e três frutos por unidade experimental. As parcelas foram constituídas de concentrações de fécula de mandioca e filme PVC e as subparcelas no intervalo de tempo da amostragem.

Os dados foram submetidos às análises de variância e regressão, utilizando o software SAEG (2007). Os modelos ajustados foram escolhidos com base na significância dos coeficientes, em nível de 5\% de probabilidade, pelo teste " $t$ ", no coeficiente de determinação e no potencial para explicar o fenômeno biológico. Independentemente da interação concentração $x$ intervalo de tempo de amostragem ser ou não significativa, optou-se pelo seu desdobramento, dado o interesse em estudo.

As perdas de massa fresca variaram de $2,1 \%$ (PVC) a 9,9\% (2\% de fécula de mandioca) no 8 dia de armazenamento (Figura 1A), com tendência de perda linear. Para CHITARRA \& CHITARRA (2005), perdas da ordem de $3 \%$ a $6 \%$ são suficientes para causar declínio na qualidade e, consequentemente, os frutos tratados com fécula $2 \%$ poderiam ser comercializados somente até quatro dias de armazenamento, enquanto os tratamentos com 3 e $1 \%$ de fécula poderiam ser comercializados até o sexto e oitavo dias, respectivamente. $\mathrm{O}$ tratamento controle também apresentou elevada perda de massa fresca $(9,2 \%)$, podendo ser comercializados até o quinto dia de armazenamento. A menor perda de massa fresca observada para os frutos revestidos com PVC ocorreu devido à barreira proporcionada pelo filme sem perfuração reduzir a perda de água para o ambiente (MALGARIM et al., 2007). 


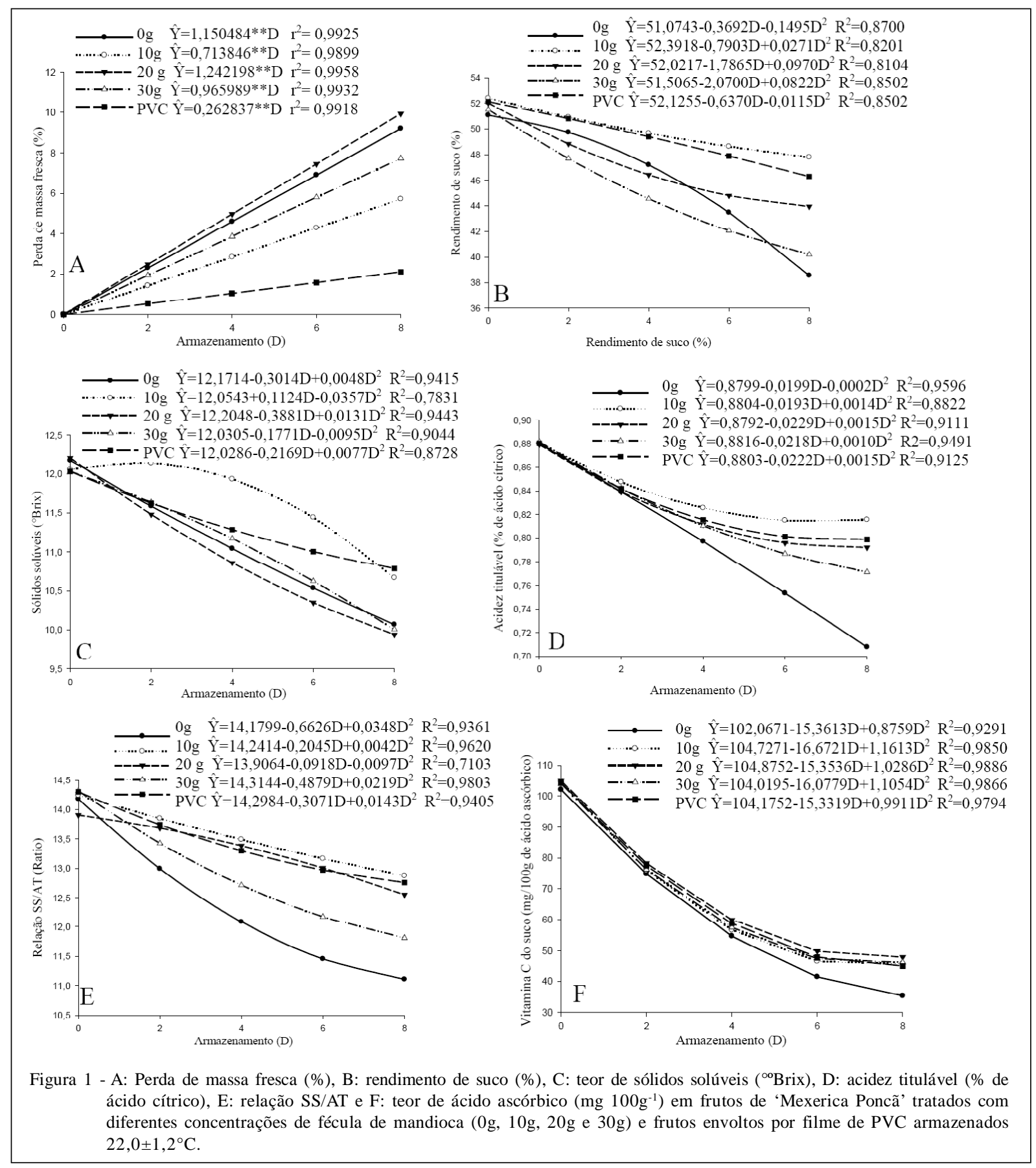

A redução no rendimento de suco não seguiu o mesmo padrão da perda de massa. Todos os tratamentos apresentaram redução de rendimento, sendo que os frutos que receberam a aplicação de $1 \%$ de fécula foram os que apresentaram o maior rendimento, após oito dias (Figura 1B), fato que pode ser explicado pela menor perda de massa fresca, uma vez que, segundo CHITARRA \& CHITARRA (2005), quando a casca realiza trocas gasosas com o ambiente, o endocarpo perde suco para a casca, resultando em reduçãono rendimento de suco. HENRIQUE \& CEREDA (2007) não verificaram redução no rendimento em suco de limão siciliano quando utilizaram fécula de mandioca. Uma possível explicação pode ser a sensibilidade diferencial das variedades. Para as maiores doses de fécula, houve descamação delas, o que levou os frutos 
a perder mais massa fresca e consequentemente reduzir o teor de suco.

Modelos quadráticos ajustaram satisfatoriamente os resultados de sólidos solúveis (SS), acidez titulável (AT), relação SS/AT e teor de ácido ascórbico, que sofreram redução durante o armazenamento (Figuras 1C, 1D, 1E e 1F). Somente frutos recobertos com filme PVC e fécula $1 \%$ apresentaram teores de sólidos solúveis maiores do que o controle (Figura 1C). Resultados semelhantes foram encontrados por ALLEONI et al. (2006) em frutos de laranja 'Pera' recobertos com concentrado proteico de soro de leite, associado a plastificantes armazenados durante 11 dias.

Frutos tratados com $1 \%$ de fécula de mandioca sofreram a menor redução de acidez durante o armazenamento, enquanto, nos frutos tratados com $0 \%$ de fécula, a redução foi significativa durante todo o período de armazenamento (Figura 1D). Segundo CHITARRA\& CHITARRA (2005), o consumo de ácidos orgânicos no processo respiratório é o principal responsável pela diminuição da acidez.

A relação SS/AT reduziu com o armazenamento, como era de se esperar, já que ambos os teores de sólidos solúveis e de acidez reduziram, sendo o maior valor observado nos frutos tratados com $1 \%$ de fécula de mandioca (Figura 1E).

Observou-se que, para o controle $(0 \%)$, a redução no teor de ácido ascórbico foi mais acentuada (Figura 1F) no decorrer do experimento. No 8o dia de armazenamento, o controle apresentou redução de aproximadamente $70 \%$, enquanto nos frutos dos demais tratamentos a redução no teor de ácido ascórbico foi de aproximadamente $40-45 \%$.

De acordo com SOARES et al. (2011), é grande o interesse pelo desenvolvimento de formulações de filmes e coberturas comestíveis aplicáveis à superfície de produtos perecíveis, como frutas. Esse fato advém da demanda crescente dos consumidores por produtos com elevada qualidade $\mathrm{e}$ vida útil prolongada. Também têm sido consideradas a redução no uso de embalagens descartáveis que não são biodegradáveis e a melhoria no sistema das embalagens recicláveis.

A concentração de fécula de mandioca a $1 \%$ foi a que proporcionou melhores resultados quanto à manutenção da vida útil pós-colheita de frutos de 'Mexerica Poncã' durante oito dias de armazenamento à temperatura ambiente, podendo substituir o filme PVC.

\section{REFERÊNCIAS}

ALLEONI, A.C.C. et al. Recobrimento de laranja 'Pera' com filme de concentrado protéico de soro de leite associado a plastificantes. Pesquisa Agropecuária Brasileira, v.41, n.8, p.1221-1226, 2006. Disponível em: <http://www.scielo.br/ s cielo.php ? s cript $=\mathrm{sci}_{-}$art text \& pi d = S $0100-$ 204X2006000800002>. Acesso em: 02 jan. 2012. doi: 10.1590/S0100-204X2006000800002.

ALVES, E.O. et al. Armazenamento refrigerado de ameixas 'Laetitia' com uso de 1-MCP e indução de perda de massa fresca. Ciência Rural, v.40, n.1, p.30-36, 2010. Disponível em: <http:/ / w w w. s c i e 1 o.br/s c i e 1 o.ph p ? p i d = S 0103 $4782010000100006 \&$ script $=$ sci_abstract $\&$ tlng $=\mathrm{pt}>$. Acesso em: 18 dez. 2011. doi: 10.1590/S0103-84782009005000251.

AOAC. Official methods of analysis of the Association of Official Analytical Chemists International. 16.ed. Washington, 1997. V.2, p.37-10, 42-42, 44-43, 45-16.

BOTREL, D.A. et al. Revestimento ativo de amido na conservação pós-colheita de pera Williams minimamente processada. Ciência Rural, v.40, n.8, p.1814-1820, 2010. Disponível em: <http://www.scielo.br/scielo.php?pid=S0103$84782010000800023 \&$ script $=$ sci_arttext $>$. Acesso em: 18 dez. 2011. doi: 10.1590/S0103-84782010000800023.

CAMPOS, R.P. et al. Post-harvest conservation of organic strawberries coated with cassava starch and chitosan. Revista Ceres, v.58, n.5, p.554-560, 2011. Disponível em: 〈http://www.scielo.br/ scielo.php?pid=S0034-737X2011000500004\&script=sci_arttex $>$. Acesso em: 16 abr. 2012. doi: 10.1590/S0034737X2011000500004.

CHITARRA, M.I.F.; CHITARRA, A.B. Pós-colheita de frutas e hortaliças: fisiologia e manuseio. 2.ed. Lavras: UFLA, 2005. 785p.

HENRIQUE, C.M.; CEREDA, M.P. Uso de ethephon e fécula de mandioca na conservação pós-colheita de limão-siciliano. Revista de Biologia e Ciências da Terra, v.7, n.1, p.99106, 2007. Disponível em: <http://eduep.uepb.edu.br/rbct/ sumarios/pdf/usodeethephon.pdf>. Acesso em: 18 dez. 2011.

MALGARIM, M.B. et al. Conservação de tangerina cv. Clemenules utilizando diferentes recobrimentos. Acta Scientiarum Agronomy, v.29, n.1, p.75-82, 2007. Disponível em: <http://periodicos.uem.br/ojs/index.php/ActaSciAgron/ article/view/69>. Acesso em: 17 abr. 2012. doi: 10.4025/ actasciagron.v29i1.69.

SAEG. Sistema para análises estatísticas, versão 9.1. Viçosa: Fundação Arthur Bernardes, UFV, 2007. CD Rom.

SCANAVACA JÚNIOR, L. et al. Uso de fécula de mandioca na pós-colheita de manga 'Surpresa'. Revista Brasileira de Fruticultura, v.29, n.1, p.067-071, 2007. Disponível em: <http://www.scielo.br/scielo.php?pid=S $0100-$ 29452007000100015\&script=sci_arttext $>$. Acesso em: 16 abr. 2012. doi: 10.1590/S0100-29452007000100015.

SOARES, N. de F.F. et al. Antimicrobial edible coating in postharvest conservation of guava. Revista Brasileira de Fruticultura, v.33, p.281-289, 2011. Disponível em: <http:/ /www.scielo.br/pdf/rbf/v33nspe1/a35v33nspe1.pdf >. Acesso em: 16 abr. 2012. doi: 10.1590/S0100-29452011000500035. 